\title{
Analysis of Influencing Factors of Migratory Tourists Behavior in Sanya
}

\author{
Gong Huiqin \\ Tourism Management College, University of Sanya, Sanya, Hainan, China, 572002
}

Keywords: "Migratory bird" tourism, influencing factors, tourist behavior characteristics

Abstract: In recent years, "migratory bird" tourism has developed rapidly, especially in coastal coastal resorts. It is also favored by people. As one of the famous coastal tourist cities in China, Sanya has become the main destination for many elderly migratory tourists. However, as the tourism of elderly migratory tourists in China is at a preliminary stage of development, the development policy for the elderly of migratory tourists is not perfect. Therefore, this paper takes the elderly migratory tourists in Sanya as an example to analyze the current and objective factors affecting the decision-making behaviors and consumption behaviors of migratory tourists. It finds out the current problems in the Sanya tourism market and provides advice for Sanya tourism companies to develop "migratory bird" tourism products and develop targeted marketing strategies.

With the rapid development of China's tourism industry, people's material life is becoming more and more abundant, and the level of consumption is getting higher and higher. More and more ordinary people choose to travel abroad to enrich their lives. As a new model of tourism and old-age care, "migrant bird tourism" has gradually been loved by the elderly in recent years. The concept of migratory bird-age care is: tourism, living and living. Retired old people have relatively more time and discretionary income, and are conditionally changed according to different seasons, ecological environment and regional climate. Like migratory tourists, they choose to go to the south to avoid the cold in the cold winter, and choose in the hot summer going to the north to escape the heat, this new and enjoyable life style is increasingly favored by elderly tourists.

However, due to the late start of migratory bird tourism in China, the unsound development of the market, the uneven development of different regions, and the imperfect policies of various support, the proportion of the elderly in China is not directly proportional to the consumption of old-age living tourism in society. Some potential elderly consumers cannot choose such a lifestyle because of some objective or subjective factors. Through the study of the influencing factors of migratory tourists in Sanya, we can further understand the tourism behavior characteristics of migratory tourists and provide guidance for the development of Sanya tourism products and the formulation of marketing strategies. 


\section{Literature Review}

\subsection{Definition of "Migrant Bird" Tourism}

At present, there is no consistency in the concept of "migratory bird "tourism. China National Tourism Administration stipulates in the Regulations on Travel Service Aged Tourism Services that elderly tourists refer to the consumption of elderly tourism products aged 60 years and older (including 60 years old). Wang Yali (2015) believes that the "migratory bird " tourism activity is a kind of tourism activity that stays in the tourist destination for a long time according to the needs of the season. Li Songbai (2005) starts from the tourist motive and considers most migratory tourists. Visitors are out of health care and recreation, and will travel to other destinations for travel and activities. Liu Fang (2017) based on the psychological perspective of the elderly tourists for nostalgia, compensation, health, and loneliness the choice to leave the permanent residence and temporarily carry out a series of tourism activities is also a migratory bird tour. In general, "migratory bird" tourism refers to the elderly consumers. In order to avoid the bad climate and ecological environment of their daily residence, and to choose a tourist destination that is more suitable for living and supporting the elderly and stays for a long time, the core appeal of the travel behavior is health and wellness.

\subsection{Behavioral Characteristics of Migratory Tourists}

Compared with the average tourist, the migratory tourists emphasize the health and wellness brought by the tourism activities and daily life, and pursue the high-quality tourism life enjoyment. Therefore, the travel plan is longer, the travel route is longer than the average tourist, and some migratory tourists even purchase real estate in tourist destinations and live for several months each year during the event season. The travel time of migratory tourists is determined according to the season of climate change. The general revisit rate is relatively high. This is the reason why most elderly people in the north choose Hainan for winter every year (Dong Hongmei, Wang Xilian, 2006). Zhu Luxi (2014) believes that the development of silver hair market will become a point that cannot be ignored in China's economy. The elderly are more concerned about physical health, and the pace of life is slow. They pursue comfort and stability during the journey. The market can develop differentiated tourism products, expand advertising and promotion, stimulate consumer demand, propose marketing strategies, and promote the development of the silver tourism market.

\subsection{Types of "Migratory Bird" Tourism}

Migratory tourists are affected by subjective and objective factors due to different travel motives. In addition to commonality, the specific behavioral characteristics are different. Therefore, they can be divided into the following types: sightseeing-type "migratory bird" tourism, family-watching "migratory bird" tourism, healing-type "migratory bird" tourism, house-type "migratory bird" tourism, investment-type "migratory bird" tourism (real estate investment, selling or renting a house to get a difference or rent), special type "migratory bird" tourism (a young mind like adventure).

\section{Sanya "Migratory Bird" Tourism Market Development Status}

\subsection{Advantages}

The development of "migratory bird" tourism in Sanya is very beneficial in terms of natural environment, economic conditions and policy orientation. First of all, Sanya has a comfortable and 
pleasant climate. It has a long summer climate, with an average temperature of 21-25 degrees Celsius. The light temperature is sufficient. The seasons are full of birds and flowers, the vegetation is lush, the climate is humid, the air is clean and pollution-free, and the negative oxygen ions are abundant. Long-term residence with elderly nursing homes. Hainan Island is known as "Longevity Island" and "Healthy Island", and Sanya also takes advantage of Hainan Island. Secondly, the Hainan government has formulated relevant policies to enlarge and strengthen Sanya's old-age service industry, develop markets for elderly tourism health, leisure, health care, education, consumer care, and cultural specialties, and establish a high-end comprehensive "international leisure pension exclusive district", and proposed to establish a medical insurance system for the elderly in different places.

\subsection{Unfavorable Conditions}

First of all, medical services lack professionalism. At present, professional medical care workers in Sanya account for only $20 \%$ of the total number of nurses. The remaining unemployed workers are mainly unemployed, lacking professional nursing knowledge and technology, and the demand for professional care workers for elderly migratory tourists. The amount is gradually increasing. Secondly, the public infrastructure is not perfect, and the public environment maintenance is not effectively managed. Therefore, in urban management, the most prominent contradiction between migratory tourists and local residents is the crowding of local public resources, which not only causes a shortage of public service resources. It is impossible to effectively and timely guide, intensify the contradiction between the host and the customer, and even cause increasingly serious cultural conflicts. Housing prices are rising once again, housing resources are wasted, and in the summer, with the return of migratory tourists, the vacancy rate of some residential quarters is as high as $90 \%$, causing serious waste of social resources.

\section{Analysis of Influencing Factors of Migrant Tourists in Sanya}

\subsection{Physical Health Factors}

From the perspective of tourism purposes, among the seven migratory tourists who choose to travel to Sanya, among the seven options related to tourism purposes, the highest proportion is to avoid the cold and winter, the elderly cannot stand the cold and dry winter in the north, and the air quality is relatively poor. It is easy to induce illness, so they prefer Sanya's beach, sunshine, and coconut island style, and can experience the tropical scenery of Sanya. However, migratory tourists will also worry about whether they can continue to come to Sanya for winter next year. The biggest obstacle is whether the health of the body can travel normally. After traveling, they will worry about whether they will suddenly develop illness in Sanya and they will not understand the local medical level. There is also no trust at all, and whether or not it can meet medical needs.

\subsection{Freely Disposable Income and Time Factors}

Data analysis showed that discretionary income and leisure time accounted for $37 \%$ of the impact on elderly travel decisions. On the one hand, Sanya tourism consumption is relatively high, migratory tourists often live for more than three months, and the cost of living is relatively high. It is necessary to pay higher fees such as transportation, accommodation, catering, medical care, leisure and entertainment, especially accommodation costs, along with the housing prices in Sanya. Increasingly, more and more migratory tourists who do not have their own houses in Sanya are unable to afford the rental expenses. Therefore, since the beginning of 2017, the sudden rise in housing prices in Sanya has led some migratory bird tourists to choose other counties and cities, even as far as Guangdong, 
Guangxi and Yunnan. Waiting for another place to find a suitable place for retirement. On the other hand, there is not enough leisure time. This is related to the traditional Chinese old-age lifestyle. Older people who have less leisure time generally have to take care of the third generation, so they cannot take their lives. Some rural elderly often have a lot of farm work. There is also a lack of awareness of vacation and retirement. These elderly people are generally retired women over 55 years of age.

\subsection{Medical Service Factors}

Most of the migratory tourists in Sanya have the need for health care or sickness. The infrastructure for geriatric care and geriatric care is more demanding than other industries. However, in the survey, services such as health care are valued by the elderly. The problem is that elderly migratory birds are generally older and have unstable physical conditions, paying more attention to health problems. Although Sanya is a tourist city, the proportion of migratory birds in the winter is very high, Sanya does not have a sound and reasonable health care system, especially for the elderly in the elderly. This invisibly increases the elderly. The difficulty of travel and the difficulty of medical treatment, during the interview process, many tourists mentioned that the neighbors of the same community in previous years were unable to travel normally due to physical discomfort this year, and chose to treat themselves in their hometown. In addition, medical treatment in different places, off-site insurance, and the use of ex-employment pensions are all major problems that need to be solved. In addition, the old-age care institutions are not perfect, and the number of professional medical staff is scarce. Many elderly people who come to Sanya also like to live in nursing homes and chat casually with the elderly of the same age. However, Sanya's old-age care institutions are uneven, some nursing homes are lacking resources, and medical staff are underserved and some Lack of communication between the old-age care institutions, poor organizational skills, and a relatively poor reputation among migratory birds.

\subsection{Tourism Safety Factors}

As a tourist city, Sanya is increasingly favored by the elderly, and has not been strengthened in the basic tourism safety awareness and urban security. Whether the construction of the safety department in the tourist sites, tourist attractions and travel agencies are complete will also affect the travel of the elderly. The convenience and safety of traffic is a hot spot for the elderly of migratory tourists. Due to safety and health considerations, they have strong demand for spas, health services, island beaches, etc. However, Sanya's current tourism products are rarely targeted at migratory tourists, including most scenic spots and rarely developed for elderly tourists' projects. When traveling, migratory tourists should consider the length of the ride, the difficulty and comfort of the event.

\section{Sanya Migratory Bird Tourist Tourism Market Development Strategy}

\subsection{Develop Distinctive "Migratory Bird" Tourism Products}

It is not only necessary to have a pleasant and pleasant climate in the local area to attract migratory tourists, but also to have perfect medical, accommodation, catering and other service facilities. Sanya has superior natural resources, and elderly migratory tourists come to Sanya to enjoy leisure vacations in addition to sheltering from the cold. Therefore, Sanya is an integrated service for the government and tourism enterprises to develop tourism, pension and medical care for this group. Since the natural environment cannot be changed, tourism products suitable for migratory tourists can be designed 
according to the consumption and physical characteristics of the elderly when developing tourism products. In the medical field, due to the older age of migratory tourists, their physical condition is different. Older people will be more concerned about their health. Therefore, different medical health products such as "healing type" and "rehabilitation type" can be developed according to the elderly of migratory tourists of different ages. In terms of accommodation, due to the inconvenience of the elderly, transportation factors and medical institutions should be considered when designing tourist accommodation. Combining accommodation, tourism, catering, etc., to continuously meet the tourist needs of the elderly, and the unique natural resources of Sanya, can make Sanya become the first choice for more elderly people.

\subsection{Improve the Medical and Health Service System}

Medical treatment in different places is an important issue for the elderly. Due to the imperfect medical system in China, some elderly people cannot settle after they have been treated in different places. The Sanya municipal government should formulate relevant policies to ensure that the elderly can carry out medical reimbursement and settlement in different places, and ensure that medical services can be implemented in every needy elderly. At the same time, we must also ensure the nationwide networking of medical information systems, simplify the procedures for the processing of migratory tourists in different places, increase the number of different medical and health service stations, reduce the restrictions on medical registration, and improve the conditions for medical treatment for migratory tourists. In addition, the government should formulate policies to improve the level of medical and health services, provide professional health services for the elderly in Sanya, and enable the elderly in Sanya to enjoy high-level medical facilities so that the elderly can have no worries while traveling.

\subsection{Introducing and Cultivating Compound Talents}

From a national perspective, the pension and leisure tourism industry lack comprehensive talents with old-age tourism services and management knowledge. Sanya is also relatively scarce in terms of human resources. Most of the employees have relatively simple skills and lack comprehensive professional knowledge and overall literacy is not high, the service level is also low, and the awareness of the work of pension and leisure tourism services is not enough. For the employees in the pension and leisure tourism industry, it is necessary to have the relevant skills of tourism services and to master certain medical maintenance skills. Therefore, the government and related enterprises need to introduce professional talents to guide the development of the industry, on the other hand, they need local Colleges and training institutions strengthen vocational training for practitioners.

\subsection{Increase Publicity Efforts}

Attracting the elderly to Sanya tourism requires not only the local natural resources, but also the local tourism companies. Tourism companies can attract developed cities and rural areas through television, internet, newspaper news advertisements and other propaganda methods. Old people in these areas have enough leisure time and disposable income and their consumption concept is relatively open. Therefore, as long as the publicity is increased and the advantages of the Sanya region are highlighted, more elderly people will come to visit and sightseeing. In addition, retired people have a strong desire for knowledge and desire to explore. They like to communicate with different people and long for the respect and attention of others. Therefore, we must increase publicity and awaken their desire to travel. 


\subsection{Safeguarding the Safety of Elderly Travel}

First of all, to improve the safety awareness of migratory tourists, the Sanya municipal government should jointly open relevant tourism safety awareness lectures. In addition, migratory tourists are older, have unstable physical conditions and travel abroad for a long time. They should undergo regular physical examinations, pay attention to travel safety, and carry essential medicines with them. Sanya is in the tropics, and mosquito bites are inevitable in tropical rain forests and other places. The drug should be applied in the first time. If you feel unwell, you should seek medical treatment promptly. Second, tourism companies must strengthen tourism security service guarantees and improve the tourism safety awareness training of the tour guide team and its employees. The tour guide team leading the migratory tourists should be required to have basic geriatric medical knowledge and be able to deal with them in case of special events. For older teams with special needs, professional medical staff can be equipped. In addition, the management of the tourism market should be strengthened, and the uncivilized phenomenon of illegal black shops and black cars is strictly prohibited from affecting the development of Sanya tourism enterprises. The government should increase its efforts to create a harmonious, safe and orderly tourist city.

\section{Acknowledgement}

Philosophy and Social Science Planning Project of Hainan Province "Sanya "Migratory Bird" Tourists Behavior Research" No. HNSK(YB)17-63

\section{References}

[1] Hongsong Ruan. Talk About Migrating Birds for Old Age [J]. Times Finance, 2012, (28): 51-52.

[2] Songbai Li. Thoughts on the Development of Senior Tourism Market in Southeast Coastal Areas[J]. Journal of Huzhou Teachers College,2005(05):89-92.

[3] Yali Wang. Development of Sanya "Migrant Bird” Old-Age Tourism Market [D]. Northwest Normal University, 2015.

[4] Liying Jiang. Analysis of the Characteristics and Significance of Tourism in the Elderly [J]. Business Economics, 2011 (23): 51-54.

[5] Hongmei Dong, Xilian Wang. On the "Migrant-Bird" Tourism of the Elderly [J]. Special Economic Zone, 2006 (06): 211-213.

[6] Luxi Zhu. Marketing Outlook of Domestic Silver Tourism Market [J]. China Market, 2014(17): 85-86.

[7] Fang Liu. Analysis of Tourism Psychology and Development Strategy of Old-age Groups in Migratory Birds [J]. Tourism Overview, 2017(04)

[8] Yuanjie Qiao, Liang Tang. Analysis of the Elderly Tourism Market in Jilin Province [J]. Cooperative Economy and Technology, 2016 (14): 119-120.

[9] Caifeng Zhou, Wenbo Ren. Analysis of the Status Quo and Development of the Elderly Tourism Market [J]. Modern Enterprise Education, 2010 (12): 87-88.

[10] Fangyan Yu. Psychological Behavior and Market Research of Tourism Consumption in the Elderly [J]. China Hightech Zone, 2017 (14): 10.

[11] Xinxin Zhang. Analysis on the Marketing Strategy of the Elderly Tourism Market in Hefei City [J]. Journal of Chifeng College (Natural Science),2017,33(03):101-103.

Gong Huiqin (1985-), Female, Han nationality, Shanxi Province, Tourism Management College, University of Sanya, Master, Lecturer, Graduate degree, mainly engaged in Tourism economy, tourism consumer behavior research. 